\title{
Increased Renal Tubular Reabsorption of Calcium and Magnesium by the Offspring of Diabetic Rat Pregnancy
}

\author{
HELEN BOND, COLIN P. SIBLEY, RICHARD J. BALMENT, AND NICK ASHTON \\ Academic Unit of Child Health [H.B., C.P.S.] and School of Biological Sciences [R.J.B., N.A.], University \\ of Manchester, Manchester, M13 9PT, United Kingdom
}

\begin{abstract}
Diabetic pregnancy has a marked influence on offspring calcium and magnesium homeostasis. Urinary excretion of calcium and magnesium is reduced, yet offspring of diabetic pregnancy exhibit hypomagnesemia and hypocalcemia. The aim of this study was to measure renal hemodynamic and tubular function in the offspring of diabetic (OD) and control, nondiabetic (OC) rats at 4 and $8 \mathrm{wk}$ of age to determine the glomerular and tubular mechanisms through which renal calcium and magnesium handling are programmed in utero. The fraction of filtered calcium that was excreted was significantly lower in OD at both 4 and 8 wk of age [ 8 wk: OC $(n=6), 11.8 \pm 2.9$ versus OD $(n$ $=5), 4.3 \pm 0.6 \% ; p<0.05]$ and that of magnesium was lower at $8 \mathrm{wk}$ of age [OC $(n=6), 42.4 \pm 7.5$ versus $\mathrm{OD}(n=5), 13.0$ $\pm 1.7 \% ; p<0.01]$. This increased reabsorption occurred despite an elevated GFR in OD. These findings clearly indicate that tubular reabsorptive mechanisms for calcium and magnesium are
\end{abstract}

\section{ABSTRACT}

increased markedly in OD. Serum PTH concentration was reduced in 8-wk-old OD [OC $(n=7), 539.4 \pm 142.1$ versus OD $(n=9), 174.3 \pm 69.4 \mathrm{pg} / \mathrm{ml} ; p<0.05]$, consistent with previous reports in human infants. Taken together, these observations suggest that the basis for the altered renal magnesium and calcium handling in OD involves increased tubular transport activity and possibly increased sensitivity of these mechanisms to PTH. (Pediatr Res 57: 890-895, 2005)

\section{Abbreviations}

M6PR, IGF-II/mannose-6-phosphate receptor

OC, offspring of control pregnancy

OD, offspring of diabetic pregnancy

PMCA, plasma membrane $\mathrm{Ca}^{2+}$-ATPase pump

STZ, streptozotocin

$\mathbf{U V}$, urine flow rate
Diabetic pregnancy has a marked impact on maternal calcium and magnesium homeostasis in both humans and rats. Hypomagnesemia has been widely reported in human diabetic pregnancy (1-3), and diabetic pregnant rats display a marked increase in urinary magnesium excretion $(4,5)$. A reduction in third-trimester plasma calcium concentration has been observed in human diabetic pregnancy in one study (3), but the majority of studies have found no difference in calcium concentrations between normal and diabetic pregnancies. However, in the diabetic rat, pregnancy is associated with marked increases in urinary calcium $(4,5)$ and hypocalcemia in some (4) but not all studies (6).

These changes in maternal divalent ion handling have a profound impact on the developing fetus. Human offspring of

Received June 30, 2004; accepted September 30, 2004.

Correspondence: Nick Ashton, Ph.D., Faculty of Life Sciences, University of Manchester, G.38 Stopford Building, Oxford Road, Manchester, M13 9PT, UK; e-mail: nick.ashton@man.ac.uk.

This study was funded by the North West Kidney Research Association.

DOI: 10.1203/01.PDR.0000157720.50808.97 diabetic pregnancy exhibit hypomagnesemia and hypocalcemia as neonates (2,7-9). In the rat, renal handling of calcium and magnesium is also altered in the offspring of streptozotocin (STZ)-treated diabetic rats (OD). We recently reported that OD retain both calcium and magnesium as neonates and that this continues into adulthood (10). These changes in divalent ion homeostasis also occur in conjunction with changes in bone structure. Human offspring of diabetic pregnancy are susceptible to congenital malformations, including skeletal abnormalities (11), and have lower bone mineral content (12). Reduced bone mineral content and abnormal skeletal development have also been observed in the offspring of STZ-treated diabetic rat mothers $(13,14)$. We recently extended these observations and showed that offspring of STZ-treated diabetic rats have reduced trabecular and higher cortical femoral bone volume that persists into adulthood (15).

The mechanisms that are responsible for this alteration in calcium and magnesium homeostasis in the offspring of diabetic pregnancy are largely unknown. In whole-kidney homogenates, we have shown that expression of the three key transport proteins that mediate the reabsorption of calcium in the 
distal nephron, namely the apical epithelial calcium channel (16), the intracellular binding protein calbindin- $\mathrm{D}_{28 \mathrm{~K}}(17)$, and the basolateral plasma membrane $\mathrm{Ca}^{2+}$-ATPase pump (PMCA) (18), is increased in the kidneys of OD rats up to the age of $16 \mathrm{wk}(10,15)$. This suggests that changes in calcium handling by the distal nephron of adult OD rats may be programmed by the in utero environment. However, as we measured only 24-h urine output using metabolism cages in our earlier study, we were not able to distinguish between renal hemodynamic and/or tubular effects that are responsible for the altered ion handling. Accordingly, the aim of this study was to assess in more detail renal function in the offspring of diabetic pregnancy to determine the relative contribution of glomerular and tubular mechanisms to the altered renal handling of calcium and magnesium in these animals. We assessed renal function in rats at $4 \mathrm{wk}$ of age, before puberty, and at $8 \mathrm{wk}$ of age, after puberty, to determine whether in utero exposure to maternal diabetes exerts a long-term programming effect on offspring kidney function. We also measured serum PTH concentration, as this has been reported to be lower in human offspring of diabetic pregnancy $(2,19,20)$ and may contribute to altered renal calcium and magnesium handling.

\section{METHODS}

All experiments described herein were performed in accordance with the UK Animals (Scientific Procedures) Act 1986 and received local ethical approval.

Animals. Twenty-five female Sprague-Dawley rats (Charles River UK Limited, Margate, Kent, UK) were used to generate the experimental animals. All animals were housed in individual cages in a room at $22-24^{\circ} \mathrm{C}$ with a $12-\mathrm{h}$ light:12-h dark cycle. Food (Rat \& Mouse Standard Diet; Bantin \& Kingman Ltd, Hull, North Humberside) and tap water were provided ad libitum.

Diabetes was induced in 11 female rats by the injection of STZ [60 mg/kg i.p. in $0.1 \mathrm{M}$ citrate buffer ( $\mathrm{pH} 4.8$ )]. Diabetes was confirmed, after $48 \mathrm{~h}$, by the development of glycosuria (Uristix; Ames DVN, Miles Ltd., Slough, UK) and hyperglycemia (blood glucose concentration $>15 \mathrm{mM}$ ). Blood for the latter was obtained via direct needle puncture of the tail vein followed by immediate assay using a blood glucose analyser (Hemocue, Sheffield, UK). Fourteen control animals received an i.p. injection of the vehicle $(0.1 \mathrm{M}$ citrate buffer $)$ alone. Urine and blood samples were taken from vehicle-injected animals to confirm that they were not diabetic.

Both control and diabetic female rats were mated with nondiabetic male rats. Pregnancy was confirmed by the appearance of a copulation plug, after which they were returned to individual housing for the remainder of the pregnancy (gestation is $21-22 \mathrm{~d}$ in the rat). An additional group of 25 vehicle-injected controls were mated at the same time. At birth, all litters that were born to both diabetic and nondiabetic mothers were fostered to this second group of vehicle-injected control dams, which had given birth on the same day, to eliminate any potential postnatal influence on offspring development. Pups were weaned at $4 \mathrm{wk}$ on to standard rat chow. Male offspring of control (OC) and diabetic (OD) mothers were studied at 4 and 8 wk of age.

Renal function at 4 and $8 \boldsymbol{w k}$. Male OC (4 wk, $n=5$ from five litters; 8 wk, $n=9$ from six litters) and OD ( $4 \mathrm{wk}, n=5$ from five litters; $8 \mathrm{wk}, n=$ 6 from five litters) were prepared for renal function study as described previously (21). Briefly, animals were anesthetized with Intraval $(100 \mathrm{mg} / \mathrm{kg}$ body wt, thiopentone sodium BP; Rhone-Poulenc Rorer Limited, Nenagh, Co Tipperary, Ireland), and cannulae were inserted into an external jugular vein, carotid artery, and the bladder. Euvolemic fluid replacement of spontaneous urine output was achieved using a servocontrolled fluid replacement system, as described previously (21). Briefly, urine flow rate (UV), determined gravimetrically, is transmitted to an adjustable pump via a computer. A program developed at the University of Manchester (22) allows the infusion rate of the pump to be automatically adjusted to precisely replace i.v. the volume of fluid lost as urine. A clearance marker $\left({ }^{3} \mathrm{H}\right.$ inulin in $2.5 \%$ dextrose, $4 \mu \mathrm{Ci} / \mathrm{h}$; Amersham International plc, Little Chalfont, Bucks, UK) for the determination of GFR was delivered via a second, slow, constant infusion pump ( $1 \mathrm{~mL} / \mathrm{h})$. After surgery, a bolus dose of ${ }^{3} \mathrm{H}$ inulin $(4 \mu \mathrm{Ci})$ was injected via the venous cannula and the servocontrolled infusion was initiated.
The infusion protocol differed between the 4-wk and 8-wk groups, as previous experience with young rats suggests that the preparation had reduced stability beyond $4 \mathrm{~h}$. Hence, the 4 -wk-old animals were allowed a 2 -h equilibration period after which urine samples were collected every $15 \mathrm{~min}$ for an additional hour. The 8 -wk-old rats were allowed a 3 -h equilibration period after which urine samples were collected every 15 min for an additional $3 \mathrm{~h}$. In both age groups, a blood sample $(0.5 \mathrm{~mL})$ was taken midway through each hour. Protein-bound and free ionized calcium were separated using Microcon YM-50 centrifugal filters (50,000-Da molecular weight cut-off; Millipore UK Ltd, Watford, UK). Blood glucose concentration was determined using a glucose analyser (Hemocue, Sheffield, UK) in a terminal blood sample at the end of the experiment. The blood glucose concentration ranged between 6 and $9 \mathrm{mM}$ in both OC and OD rats in each age group.

Analysis. Urine and plasma sodium concentrations were measured by flame photometry (Corning 480; Corning Ltd, Halstead, Essex, UK), and calcium and magnesium concentrations were measured by atomic absorption spectrophotometry (model 3100; Perkin Elmer, Beaconsfield, Bucks, UK). ${ }^{3} \mathrm{H}$ inulin was determined using a 1900CA Tri-Carb Liquid Scintillation Analyser $\beta$-counter (Canberra Industries, Meriden, CT).

PTH RIA. Serum was collected from a separate group of 8-wk-old rats (OC, $n=7$; OD, $n=9$ ). PTH concentrations were measured using a rat PTH immunoradiometric assay kit (Nichols Diagnostics, Cambridge, UK), as described previously (23).

Calculations and statistical analysis. GFR was calculated as the clearance of inulin [urinary (inulin) $\times \mathrm{UV} /$ plasma (inulin) $\mathrm{ml} / \mathrm{min}$ ]. The clearance of electrolytes was calculated as urinary (electrolyte) $\times \mathrm{UV} /$ plasma (electrolyte) $\mathrm{ml} / \mathrm{min}$. Fractional excretion of electrolytes was calculated as [urinary (electrolyte) $\times$ UV/plasma (electrolyte) $\times$ GFR] $\times 100 \%$. Data are presented as the mean \pm SEM, corrected for body weight where appropriate. As the primary manipulation was of the mother rather than the offspring, $n$ represents the number of litters. No more than three rats per litter were used at either age. Statistical analysis of renal data were by repeated measures ANOVA, with $p$ $\leq 0.05$ considered significant (SPSS for Windows, version 10.1.0; SPSS UK Ltd, Surrey, UK). As all measured renal parameters remained stable in both OC and OD groups over the 1-h (4 wk) and 3-h ( $8 \mathrm{wk})$ collection periods, data have been combined and are presented as a single mean \pm SEM value. Body weights, plasma electrolytes, and serum PTH concentrations were compared using an independent samples $t$ test.

\section{RESULTS}

Renal function at $4 \boldsymbol{w k}$. Neither body weight [OC $(n=5)$, $96.0 \pm 4.8$ versus $\mathrm{OD}(n=5), 100.0 \pm 8.8 \mathrm{~g} ; p=0.7]$ nor systolic blood pressure (OC $108 \pm 4$ versus OD $108 \pm 7 \mathrm{~mm}$ $\mathrm{Hg} ; p=1.0)$ differed between $\mathrm{OC}$ and $\mathrm{OD}$ at 4 wk of age. Plasma sodium and magnesium concentrations were also comparable between the two groups. However, the plasma concentration of ionized calcium was significantly higher in OD rats (OC $1.01 \pm 0.01$ versus OD $1.18 \pm 0.06 \mathrm{mmol} / \mathrm{L} ; p=0.04$ ).

GFR $(p=0.001)$ and UV $(p=0.025)$ both were significantly higher in OD compared with OC rats (Fig. 1). Urinary sodium excretion ( $p=0.004$; Fig. 1) and sodium clearance [OC $(n=5), 47.7 \pm 3.6$ versus $\mathrm{OD}(n=5), 10.6 \pm 0.6 \mu \mathrm{L}$. $\min ^{-1} \cdot 100 \mathrm{~g}$ body $\left.\mathrm{wt}^{-1} ; p=0.004\right]$ were higher in OD animals. However, fractional excretion of sodium did not differ ( $p=0.7$; Fig. 1 ); thus, the higher rates of sodium excretion reflected the higher GFR of OD rats rather than any changes in tubular reabsorption of filtered sodium.

In contrast, in the face of the higher filtered load of ions in $\mathrm{OD}$, urinary calcium excretion was similar in the two groups. Fractional excretion of calcium was significantly lower $(p=$ 0.014) in the OD rats (Fig. 2), indicating substantially increased tubular reabsorption of calcium. Calcium clearance, accordingly, was comparable between $\mathrm{OC}$ and $\mathrm{OD}$ animals [OC $(n=5), 45.9 \pm 3.3$ versus $\mathrm{OD}(n=5), 39.8 \pm 6.1 \mu \mathrm{L}$. $\min ^{-1} \cdot 100 \mathrm{~g}$ body $\left.\mathrm{wt}^{-1} ; p=0.4\right]$. Urinary magnesium excretion ( $p=0.67$; Fig. 2$)$ and magnesium clearance [OC $(n$ $=5), 184.8 \pm 41.9$ versus $\mathrm{OD}(n=5), 194.1 \pm 54.6 \mu \mathrm{L}$. 

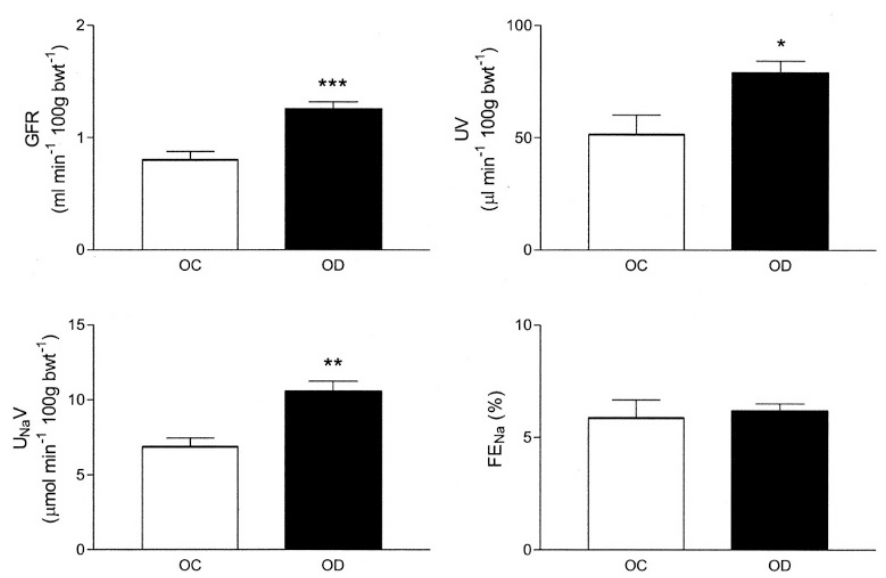

Figure 1. GFR, UV, sodium excretion $\left(\mathrm{U}_{\mathrm{Na}} \mathrm{V}\right)$, and fractional sodium excretion $\left(\mathrm{FE}_{\mathrm{Na}}\right)$ in 4-wk-old $\mathrm{OC}(\square ; n=5$ from five litters) and OD ( $\square ; n=5$ from five litters). Statistical comparisons were by repeated measures ANOVA. As all measured renal parameters remained stable in both OC and OD groups over the 1-h experimental period, data have been combined and are presented as a single mean \pm SEM value. $* p<0.05, * * p<0.01, * * * p<0.001$ OC $v s$ OD.
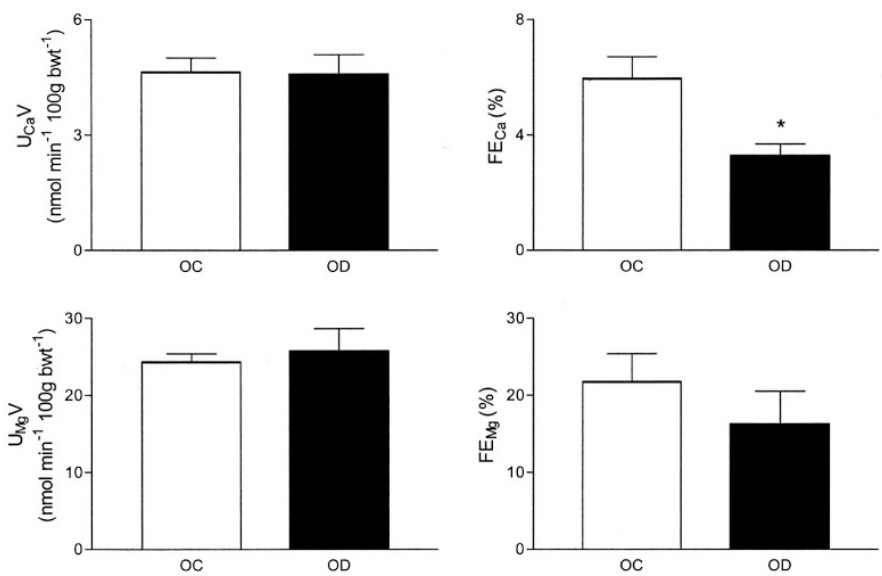

Figure 2. Calcium excretion $\left(\mathrm{U}_{\mathrm{Ca}} \mathrm{V}\right)$, fractional calcium excretion $\left(\mathrm{FE}_{\mathrm{Ca}}\right)$, magnesium excretion $\left(\mathrm{U}_{\mathrm{Mg}} \mathrm{V}\right)$, and fractional magnesium excretion $\left(\mathrm{FE}_{\mathrm{Mg}}\right)$ in 4-wk-old OC ( $\square ; n=5$ from 5 litters) and OD ( $\square ; n=5$ from five litters). Statistical comparisons were by repeated measures ANOVA. As all measured renal parameters remained stable in both OC and OD groups over the 1-h experimental period, data have been combined and are presented as a single mean \pm SEM value. ${ }^{*} p<0.05$ OC vs OD.

$\min ^{-1} \cdot 100 \mathrm{~g}$ body wt ${ }^{-1} ; p=0.89$ ] did not differ between the groups. Again, the higher filtered load of magnesium seems to have been compensated by increased tubular reabsorption, although the lower fractional magnesium excretion was not statistically different from OC ( $p=0.35$; Fig. 2$)$.

Renal function at $8 \boldsymbol{w} \boldsymbol{k}$. Body weight [OC $(n=6), 403.9 \pm$ 6.0 versus $\mathrm{OD}(n=5), 365.8 \pm 19.1 \mathrm{~g} ; p=0.1]$ and systolic blood pressure (OC $123 \pm 9$ versus OD $124 \pm 4 \mathrm{~mm} \mathrm{Hg} ; p=$ 0.92 ) remained comparable between $\mathrm{OC}$ and $\mathrm{OD}$ at $8 \mathrm{wk}$ of age. Plasma sodium, calcium, and magnesium concentrations did not differ between the two groups.

GFR $(p=0.001)$ and UV $(p=0.005)$ remained higher in OD at 8 wk of age (Fig. 3). In contrast to the pattern at 4 wk, urinary sodium excretion (Fig. 3 ) and sodium clearance [OC ( $n$ $=6), 13.1 \pm 4.9$ versus $\mathrm{OD}(n=5), 18.9 \pm 1.8 \mu \mathrm{L} \cdot \min ^{-1}$
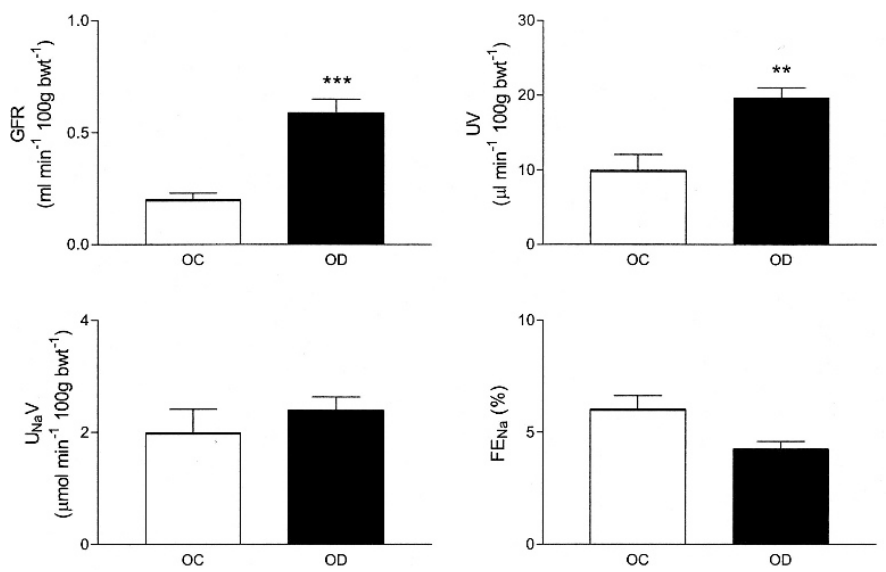

Figure 3. GFR, UV, $\mathrm{U}_{\mathrm{Na}} \mathrm{V}$, and $\mathrm{FE}_{\mathrm{Na}}$ in 8-wk-old $\mathrm{OC}(\square ; n=9$ from six litters) and OD ( $\square ; n=6$ from five litters). Statistical comparisons were by repeated measures ANOVA. As all measured renal parameters remained stable in both OC and OD groups over the 3-h experimental period, data have been combined and are presented as a single mean \pm SEM value. ${ }^{* *} p<0.01, * * * p$ $<0.001$ OC vs OD.

. $100 \mathrm{~g}_{\text {body }} \mathrm{wt}^{-1} ; p=0.31$ ] by OD rats were no longer different from those of OC rats. Fractional excretion of sodium, although lower in OD rats, did not differ significantly between groups at 8 wk of age (Fig. 3).

Renal calcium handling by 8 -wk-old OD rats was similar to that seen at $4 \mathrm{wk}$. Urinary calcium excretion did not differ between OD and OC rats (Fig. 4), and calcium clearance was comparable between the two groups [OC $(n=6), 14.7 \pm 2.0$ versus $\mathrm{OD}(n=5), 19.3 \pm 2.3 \mu \mathrm{L} \cdot \min ^{-1} \cdot 100 \mathrm{~g}$ body wt ${ }^{-1}$; $p=0.154]$. Again, this reflected increased tubular reabsorption such that the fractional excretion of calcium by OD rats was $63 \%$ lower than that of OC rats $(p=0.035$; Fig. 4). Magnesium handling followed the same pattern. Magnesium excretion did not differ (Fig. 4), and magnesium clearance was comparable between the two groups [OC $(n=6), 74.1 \pm 12.9$ versus $\mathrm{OD}(n=5), 59.7 \pm 5.8 \mu \mathrm{L} \cdot \min ^{-1} \cdot 100 \mathrm{~g}$ body wt $^{-1}$; $p=0.4]$. This resulted from enhanced tubular reabsorption;
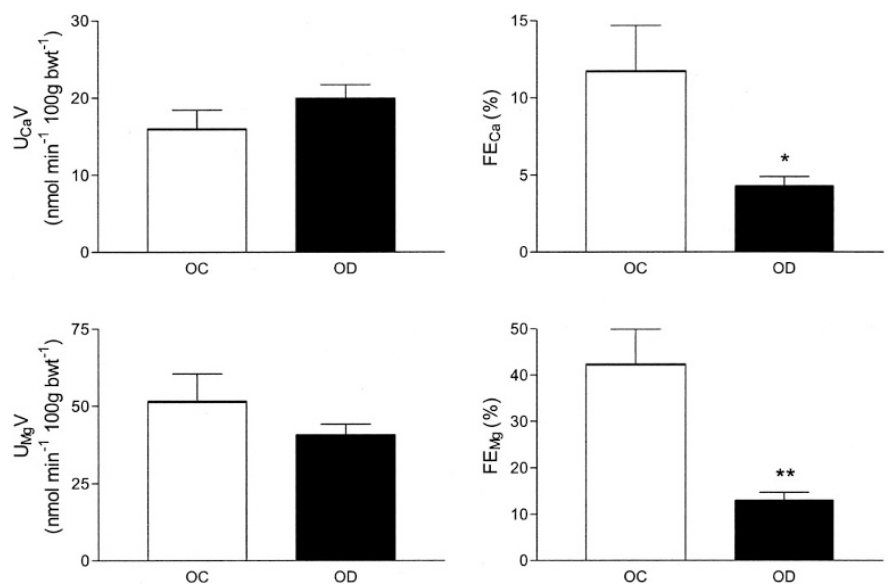

Figure 4. $\mathrm{U}_{\mathrm{Ca}} \mathrm{V}, \mathrm{FE}_{\mathrm{Ca}}, \mathrm{U}_{\mathrm{Mg}} \mathrm{V}$, and $\mathrm{FE}_{\mathrm{Mg}}$ in 8-wk-old $\mathrm{OC}(\square ; n=9$ from six litters) and OD ( $\square ; n=6$ from five litters). Statistical comparisons were by repeated measures ANOVA. As all measured renal parameters remained stable in both OC and OD groups over the 3-h experimental period, data have been combined and are presented as a single mean \pm SEM value. $* p<0.05$, * $*$ $<0.01$ OC vs OD. 
thus, fractional excretion of magnesium was significantly lower in OD rats ( $p=0.005$; Fig. 4 ). The serum concentration of PTH was significantly lower in OD compared with OC rats [OC $(n=7), 539.4 \pm 142.1$ versus OD $(n=9), 174.3 \pm 69.4$ $\mathrm{pg} / \mathrm{ml} ; p=0.026$ ) at 8 wk of age.

\section{DISCUSSION}

Hypomagnesemia and hypocalcemia have been widely reported in the neonatal offspring of human diabetic pregnancy (2,7-9), despite recent observations that show a reduction in urinary calcium and magnesium excretion by children who are born to diabetic mothers (24). This study has demonstrated that offspring that are born to mothers with diabetes maintain altered renal function, in particular enhanced tubular reabsorption of calcium and magnesium, under the conditions of renal clearance analysis used herein. This was associated with a reduction in serum PTH concentration. These observations extend our previous report of a reduction in 24-h calcium and magnesium output in metabolism cage studies in OD at 0,8 , 12 , and 16 wk of age $(5,10,15)$. In the current study, the reductions in fractional excretion of calcium and magnesium occurred despite a concurrent increase in GFR in OD rats. Renal hyperfiltration is widely reported in diabetic rats; suggested mechanisms include glucosuria-mediated osmotic diuresis (25), a reduction in tubuloglomerular feedback (26), increased glomerular arginine uptake (27), increased nitric oxide generation (28), and renal sympathetic nerve activity (29). These mechanisms have not been explored in OD rats, so the reason(s) for the increase in GFR observed in OD in the current study remains unclear.

An increase in GFR leads to an increase in the filtered load of ions, but despite this, reabsorption of calcium and magnesium remained enhanced. In contrast, UVs were elevated in both age groups and sodium excretion was increased in 4-wkold OD rats. This suggests that there was no tubular compensation in the handling of water and sodium, whereas markedly enhanced calcium and magnesium tubular reabsorptive transport is a characteristic feature in OD. Hence, the observed reduction in fractional excretion of calcium and magnesium seems to reflect specific alterations in renal tubular handling of these ions by OD animals.

Calcium reabsorption occurs both in the proximal tubule, via a passive paracellular pathway, and in the distal nephron, via a hormone-regulated transcellular route (30). We demonstrated recently that expression of all three key distal tubular transport proteins, epithelial calcium channel, calbindin- $\mathrm{D}_{28} \mathrm{~K}$, and PMCA, is increased in homogenates of whole kidneys from both neonatal and adult rats that are born to diabetic mothers $(10,15)$, which is consistent with the reduction in the fractional excretion of calcium reported herein (31). Taken together with our previous observations of reduced calcium excretion in OD from neonates to $16 \mathrm{wk}$ of age $(5,10,15)$, these data suggest that expression of renal calcium transporter protein and tubular calcium reabsorption are programmed in utero in the OD rat to exceed that of the normal animal.

Like humans, diabetic pregnancy in the rat is associated with hypercalciuria (5) and hypocalcemia of the mother (4).
Placental calcium content is reduced in pregnant diabetic rats (32), and maternofetal calcium flux across the placenta is also reduced (6). This probably occurs as a result of a reduction in the placental calcium binding protein calbi$\operatorname{ndin}_{9} \mathrm{~K}(6,33)$, which translocates calcium across the trophoblast cytosol (34), resulting in fetal calcium deficiency in utero. This background, accordingly, may promote a calcium retention strategy by the developing fetal kidney that then seems to persist post partum.

This may be exacerbated by the effects of hyperglycemia on the developing kidney. Glucose readily crosses the placenta down a maternofetal concentration gradient; hence, the fetuses of diabetic rats have elevated plasma glucose concentrations as a result of their mother's hyperglycemia (35). Exposure of the developing metanephros to high glucose concentrations, either in vitro or in vivo by STZinduced maternal diabetes or maternal glucose infusion, inhibits nephrogenesis (36). As a result, the offspring of diabetic pregnancy have $10-35 \%$ fewer nephrons (36). The mechanisms involved are not fully understood but seem to involve up-regulation of the IGF-II/mannose-6-phosphate receptor (M6PR) (37). IGF-II, which plays an important role in renal organogenesis (38), is internalized and degraded by M6PR (39). M6PR expression is increased in the metanephroi of fetuses that are exposed to diabetes in utero (37), remaining higher than control animals up to day 20 of gestation (40). It has been suggested that this contributes to the impaired nephrogenesis in fetuses of diabetic mothers (40). We did not determine nephron number in the current study, but it is reasonable to assume that nephrogenesis was impaired in OD animals. Because whole-kidney GFR was increased in OD, single-nephron GFR must be markedly higher in these animals, resulting in higher filtered loads of electrolytes. An increase in the tubular delivery of calcium may also contribute to the up-regulation in calcium transport proteins observed in our earlier studies $(10,15)$.

Magnesium is reabsorbed primarily in the thick ascending limb via a paracellular route, with some reabsorption in the proximal tubule and hormone-mediated uptake in the distal tubule (41). Mammalian magnesium transporters have yet to be cloned, but the transport characteristics of the distal nephron have been described. Apical uptake seems to be passive, through a putative magnesium channel (41), whereas movement across the basolateral membrane is against both electrical and concentration gradients. There is evidence for $\mathrm{a} \mathrm{Na}^{+} / \mathrm{Mg}^{2+}$ exchanger (42) and a $\mathrm{Mg}^{2+}$-ATPase pump (41), which may be linked to the activity of the $\mathrm{Ca}^{2+}$-ATPase pump (PMCA) (43). Distal tubular magnesium reabsorption is also load dependent; increased delivery of magnesium to the distal tubule results in an increase in reabsorption (44). Thus, it is possible that the increase in fractional magnesium reabsorption observed in the current study reflects an increase in distal tubular flow, arising from the associated increase in GFR. However, this may be aggravated by maternal magnesium depletion associated with pregnancy and exacerbated by diabetes (45). Human studies reveal a reduction in amniotic fluid magnesium concentration in diabetic pregnancy (46), which is associated with hypomag- 
nesemia in the infant (9). The situation in the rat seems to be slightly different, as plasma magnesium concentrations were not altered in OD in the current study at 4 and $8 \mathrm{wk}$ of age. However, we have shown previously that maternofetal magnesium flux across the placenta is reduced in pregnant diabetic rats (6), suggesting that the rat fetus is magnesium deficient. This could program the fetal kidney to retain magnesium as well as calcium. This hypothesis warrants further investigation once the molecular identity of the renal magnesium transporters has been described.

The serum PTH concentration of 8-wk-old OD was lower than that of $\mathrm{OC}$ rats in the current study, which is in accordance with observations in human neonates $(2,19,20)$. A number of hypotheses have been proposed to account for the apparent paradox of hypocalcemia and low PTH concentration. Bergman et al. (19) suggested that the fall in glucose and consequent increase in glucagon that arises in the neonate post partum stimulates an increase in calcitonin secretion. This inhibits bone resorption and results in hypocalcemia despite low PTH concentrations. Loughead et al. (47) suggested that hypomagnesemia blunts the parathyroid secretory response to hypocalcemia, leading to an inappropriately low PTH concentration. However, these proposed mechanisms do not account for the observations made in the current study. At $8 \mathrm{wk}$ of age, serum PTH was lower in OD, yet both plasma magnesium and calcium concentrations were no different from OC rats. Fractional excretion of magnesium and calcium was considerably lower in OD rats in the face of this reduction in PTH, which is known to stimulate both magnesium and calcium reabsorption (48). These observations suggest that not only the renal tubular reabsorptive mechanism(s) for magnesium and calcium transport but also their sensitivity to PTH action may be programmed in utero. Preliminary data suggest that there may be similar effects on renal function in children who are born to women with diabetes in pregnancy (24). The mechanisms by which maternal diabetes induces these alterations in renal divalent ion handling now require attention.

\section{REFERENCES}

1. Cruikshank DP, Pitkin RM, Reynolds WA, Williams GA, Hargis GK 1980 Altered maternal calcium homeostasis in diabetic pregnancy. J Clin Endocrinol Metab 50:264-267

2. Cruikshank DP, Pitkin RM, Varner MW, Williams GA, Hargis GK 1983 Calcium metabolism in diabetic mother, fetus, and newborn infant. Am J Obstet Gynecol 145:1010-1016

3. Mimouni F, Tsang RC, Hertzberg VS, Neumann V, Ellis K 1989 Parathyroid hormone and calcitriol changes in normal and insulin-dependent diabetic pregnancies. Obstet Gynecol 74:49-54

4. Verhaeghe J, Bouillon R, Nyomba BL, Lissens W, Van Assche FA 1986 Vitamin D and bone mineral homeostasis during pregnancy in the diabetic BB rat. Endocrinology 118:1019-1025

5. Birdsey TJ, Husain SM, Garland HO, Sibley CP 1995 The effect of diabetes mellitus on urinary calcium excretion in pregnant rats and their offspring. J Endocrinol 145:11-18

6. Husain SM, Birdsey TJ, Glazier JD, Mughal MZ, Garland HO, Sibley CP 1994 Effect of diabetes mellitus on maternofetal flux of calcium and magnesium and calbindin ${ }_{9 K}$ mRNA expression in rat placenta. Pediatr Res 35:376-381

7. Tsang RC, Strub R, Brown DR, Steichen J, Hartman C, Chen IW 1976 Hypomagnesemia in infants of diabetic mothers: perinatal studies. J Pediatr 89:115-119

8. Tsang RC, Kleinman LI, Sutherland JM, Light IJ 1972 Hypocalcemia in infants of diabetic mothers. Studies in calcium, phosphorus, and magnesium metabolism and parathormone responsiveness. J Pediatr 80:384-395

9. Mimouni F, Tsang RC, Hertzberg VS, Miodovnik M 1986 Polycythemia, hypomagnesemia, and hypocalcemia in infants of diabetic mothers. Am J Dis Child 140:798 800
10. Bond H, Hamilton K, Glazier J, Sibley CP, Balment RJ 2002 Renal calcium homeostasis, calbindin- $\mathrm{D}_{28 \mathrm{~K}}$ and plasma calcium ATPase (PMCA) expression in the offspring of diabetic rats. J Physiol 544P:94P

11. Soler NG, Walsh CH, Malins JM 1976 Congenital malformations in infants of diabetic mothers. Q J Med 45:303-313

12. Mimouni F, Steichen JJ, Tsang RC, Hertzberg V, Miodovnik M 1988 Decreased bone mineral content in infants of diabetic mothers. Am J Perinatol 5:339-343

13. Mishima N, Sahara N, Shirakawa M, Ozawa H 2002 Effect of streptozotocininduced diabetes mellitus on alveolar bone deposition in the rat. Arch Oral Biol 47:843-849

14. Braddock R, Siman CM, Hamilton K, Garland HO, Sibley CP 2002 Gamma-linoleic acid and ascorbate improves skeletal ossification in offspring of diabetic rats. Pediatr Res 51:647-652

15. Bond H, Balment RJ, Freemont A, Glazier J, Hamilton K, Sibley CP 2003 Altered renal calcium homeostasis and bone formation in the adult offspring of diabetic rats. Pediatr Res 53(suppl):27A

16. Hoenderop JG, van der Kemp AW, Hartog A, van de Graaf SF, van Os CH, Willems $\mathrm{PH}$, Bindels RJ 1999 Molecular identification of the apical $\mathrm{Ca}^{2+}$ channel in 1, 25-dihydroxyvitamin $\mathrm{D}_{3}$-responsive epithelia. J Biol Chem 274:8375-8378

17. Borke JL, Caride A, Verma AK, Penniston JT, Kumar R 1989 Plasma membrane calcium pump and $28-\mathrm{kDa}$ calcium binding protein in cells of rat kidney distal tubules. Am J Physiol 257:F842-F849

18. Lehotsky J, Kaplan P, Murin R, Raeymaekers L 2002 The role of plasma membrane $\mathrm{Ca}^{2+}$ pumps (PMCAs) in pathologies of mammalian cells. Front Biosci 7:d53-d84

19. Bergman L, Kjellmer I, Selstam U 1974 Calcitonin and parathyroid hormonerelation to early neonatal hypocalcemia in infants of diabetic mothers. Biol Neonate 24:151-160

20. Schedewie HK, Odell WD, Fisher DA, Krutzik SR, Dodge M, Cousins L, Fiser WP 1979 Parathormone and perinatal calcium homeostasis. Pediatr Res 13:1-6

21. Ahmed MH, Ashton N, Balment RJ 2003 The effect of chloroquine on renal function and vasopressin secretion: a nitric oxide-dependent effect. J Pharmacol Exp Ther 304:156-161

22. Burgess WJ, Shalmi M, Petersen JS, Plange-Rhule J, Balment RJ, Atherton JC 1993 A novel computer-driven, servo-controlled fluid replacement technique and its application to renal function studies in conscious rats. Clin Sci (Lond) $85: 129-137$

23. Hamilton K, Tein M, Glazier J, Mawer EB, Berry JL, Balment RJ, Boyd RD, Garland HO, Sibley CP 2000 Altered calbindin mRNA expression and calcium regulating hormones in rat diabetic pregnancy. J Endocrinol 164:67-76

24. Mughal MZ, Eelloo J, Sibartie S, Roberts SA, Maresh M, Sibley CP, Adams JE 2003 Intrauterine programming of urinary calcium and magnesium excretion in children born to mothers with insulin dependent diabetes mellitus. J Bone Miner Res 18(suppl):S172

25. Ward DT, Yau SK, Mee AP, Mawer EB, Miller CA, Garland HO, Riccardi D 2001 Functional, molecular, and biochemical characterization of streptozotocin-induced diabetes. J Am Soc Nephrol 12:779-790

26. Thomson SC, Deng A, Bao D, Satriano J, Blantz RC, Vallon V 2001 Ornithine decarboxylase, kidney size, and the tubular hypothesis of glomerular hyperfiltration in experimental diabetes. J Clin Invest 107:217-224

27. Schwartz IF, Iaina A, Benedict Y, Wollman Y, Chernichovski T, Brasowski E, Misonzhnik F, Ben-Dor A, Blum M, Levo Y, Schwartz D 2004 Augmented arginine uptake, through modulation of cationic amino acid transporter-1, increases GFR in diabetic rats. Kidney Int 65:1311-1319

28. Ito A, Uriu K, Inada Y, Qie YL, Takagi I, Ikeda M, Hashimoto O, Suzuka K, Eto S, Tanaka Y, Kaizu K 2001 Inhibition of neuronal nitric oxide synthase ameliorates renal hyperfiltration in streptozotocin-induced diabetic rat. J Lab Clin Med 138:177185

29. Luippold G, Beilharz M, Muhlbauer B 2004 Chronic renal denervation prevents glomerular hyperfiltration in diabetic rats. Nephrol Dial Transplant 19:342-347

30. Friedman PA 2000 Mechanisms of renal calcium transport. Exp Nephrol 8:343-350

31. Bronner F, Stein WD 1988 CaBPr facilitates intracellular diffusion for Ca pumping in distal convoluted tubule. Am J Physiol 255:F558-F562

32. Uriu-Hare JY, Stern JS, Reaven GM, Keen CL 1985 The effect of maternal diabetes on trace element status and fetal development in the rat. Diabetes 34:1031-1040

33. Verhaeghe J, Thomasset M, Brehier A, Van Assche FA, Bouillon R 1988 $1,25(\mathrm{OH})_{2} \mathrm{D}_{3}$ and Ca-binding protein in fetal rats: relationship to the maternal vitamin D status. Am J Physiol 254:E505-E512

34. Glazier JD, Atkinson DE, Thornburg KL, Sharpe PT, Edwards D, Boyd RD, Sibley CP 1992 Gestational changes in $\mathrm{Ca}^{2+}$ transport across rat placenta and mRNA for calbindin $_{9 \mathrm{~K}}$ and $\mathrm{Ca}^{2+}$-ATPase. Am J Physiol 263:R930-R935

35. Holemans K, Van Bree R, Verhaeghe J, Meurrens K, Van Assche FA 1997 Maternal semistarvation and streptozotocin-diabetes in rats have different effects on the in vivo glucose uptake by peripheral tissues in their female adult offspring. J Nutr 127:13711376

36. Amri K, Freund N, Vilar J, Merlet-Benichou C, Lelievre-Pegorier M 1999 Adverse effects of hyperglycemia on kidney development in rats: in vivo and in vitro studies. Diabetes 48:2240-2245

37. Amri K, Freund N, Van Huyen JP, Merlet-Benichou C, Lelievre-Pegorier M 2001 Altered nephrogenesis due to maternal diabetes is associated with increased expression of IGF-II/mannose-6-phosphate receptor in the fetal kidney. Diabetes 50:10691075

38. Hammerman MR 1995 Growth factors in renal development. Semin Nephrol 15:291299 
39. Braulke T 1999 Type-2 IGF receptor: a multi-ligand binding protein. Horm Metab Res 31:242-246

40. Duong Van Huyen JP, Amri K, Belair MF, Vilar J, Merlet-Benichou C, Bruneval P, Lelievre-Pegorier M 2003 Spatiotemporal distribution of insulin-like growth factor receptors during nephrogenesis in fetuses from normal and diabetic rats. Cell Tissue Res 314:367-379

41. Dai LJ, Ritchie G, Kerstan D, Kang HS, Cole DE, Quamme GA 2001 Magnesium transport in the renal distal convoluted tubule. Physiol Rev 81:51-84

42. Gunther $\mathrm{T} 1993$ Mechanisms and regulation of $\mathrm{Mg}^{2+}$ efflux and $\mathrm{Mg}^{2+}$ influx. Miner Electrolyte Metab 19:259-265

43. Flatman PW 1984 Magnesium transport across cell membranes. J Membr Bio 80:1-14
44. Quamme GA 1981 Effect of furosemide on calcium and magnesium transport in the rat nephron. Am J Physiol 241:F340-F347

45. Mimouni F, Miodovnik M, Tsang RC, Holroyde J, Dignan PS, Siddiqi TA 1987 Decreased maternal serum magnesium concentration and adverse fetal outcome in insulin-dependent diabetic women. Obstet Gynecol 70:85-88

46. Mimouni F, Miodovnik M, Tsang RC, Callahan J, Shaul P 1987 Decreased amniotic fluid magnesium concentration in diabetic pregnancy. Obstet Gynecol 69:12-14

47. Loughead JL, Mimouni F, Tsang RC, Khoury JC 1991 A role for magnesium in neonatal parathyroid gland function? J Am Coll Nutr 10:123-126

48. de Rouffignac C, Quamme G 1994 Renal magnesium handling and its hormona control. Physiol Rev 74:305-322 